Session 2525

\title{
EXPLORING PERSONAL, HYPER-ACTIONS IN ENGINEERING ETHICS- Having your Cake and Being Able to Eat It To!
}

Francis A. Di Bella, PE (617-373-5240, fdibella@ coe.neu.edu)

\author{
Assistant Professor, Northeastern University \\ School of Engineering Technology
}

\begin{abstract}
The engineering profession has been able to maintain its reputation for high professional ethics behavior. The infrequent newspaper article that does reveal a shortcoming in professional engineering ethics remains news worthy simply because they are rare in the professional world. Under extreme circumstances the professional engineer is often tempted to rationalize an ethical position in lieu of not receiving permission to enact responsible action from an employer. The consequence may be for the professional to commit the ultimate sacrifice: needing to quit the job in order to avoid an unethical situation. This ultimate sacrifice affects the professional's family and may have a long lasting effect on the morale and future discipline of the professional. This paper will explore the methods for a professional engineer to maintain professional ethics while dealing with the diversity of ethical dilemmas in engineering practice. The principle-ofaction espoused in this paper is the positive-attitude dictum that is so necessary in any engineering endeavor: that there is a viable solution to every ethical situation just as there must be confidence that there's a solution to every engineering problem. This paper will explore the ways that engineers can transform a seemingly intangible problem into one that can be solved with professional engineering expertise, thus maintaining professional ethics.
\end{abstract}

\section{Introduction:}

During the height of the Vietnam war years, the anti-war intentions of many were clearly expressed with the question: "What if they called a war and nobody came?" This paper's intent with regard to ethical dilemmas that many engineers face might be stated along similar lines: What if an ethical dilemma arises and all professional engineers refused to "go along". What if the engineer stands his/her ground, competently, confidently and professionally, simply refuses to participate in any action that will denigrate not only him/herself but also the profession; borrowing a philosophy as espoused in another worn but a powerful phrase (this time from the eighties) "...just says NO!"’.

"Proceedings of the 2001 American Society for Engineering Education Annual Conference \& Exposition Copyright $($ ) 2001, American Society of Engineering Education 
At this point the author can "hear" the experienced reader mutter: It's not that easy. There are repercussions from obvious, defiant stances". Perhaps, but what if the engineer is so supremely empowered, emotionally and professionally, that he/she participates only in the manner that he/she has been trained, that is, by applying competent engineering to resolve the technical issue that has likely to have been the cause of the ethical dilemma?

But then what if the administrators of the ethical dilemma are adamant and persists as only the Manager -in-charge, i.e.: the Boss can? Can the professional engineer simply stand his/her ground, to continue to offer engineering solutions until the perpetrators are forced into some positive action such as the implementation of one of the suggested remedy(s)? What can be the alternative to taking positive action if the professional engineer presents a steadfast but professionally cooperative demeanor? Do the perpetrators of an ethical dilemma choose to take a legally indefensible action such as dismissing the engineer on the grounds of ... of What? Professionalism? Cannot the enabled engineer thus effectively turn the tables on the perpetrator of the ethical dilemma? Will the problem go away? Or will the ethical dilemma only be shifted to a weaker engineer?

This paper discusses some of this dilemma and suggests that there's an effective means of encountering the ethical question, resolve it to the satisfaction of the issuer and to the ethical maintenance of the engineer. It is the author's contention that through selfreliance, which is bolstered by the engineer's competence, confidence and charisma, the engineer advances his/her moral autonomy to an extent that he/she becomes less vulnerable to the onslaught and/or temptation of committing an ethical violation of the engineer's creed or of humanity's moral imperative. This viewpoint is seen to be in concurrence with that of Messrs. Martin and Schinzinger ("Ethics in Engineering", 2nd Edition, pg. 75) who state: “...people are morally autonomous when their moral conduct and principles of action are their own....". Similarly the thoughts of Mr. Schwab (Nov., 2000, IEEE pg.23): “Applied ethics, goes beyond principals...is based on respect for humanity, recognizing dilemmas, relies on "good" individual judgment, encourages personal responsibility, and requires compliance with applicable "moral Standards".

\section{Who is susceptible to ethical failings?}

Clearly, wherever there are human beings who have relative freedom to decide between moral paths then there will be ethical dilemmas. Given that this paper discusses the human ethical failings or successes of that unique class of individuals called engineers then attention in this paper will be focused on this subset of the human population. Are self-employed engineers more susceptible to ethical failings than those who are on a company's payroll? Are famous (as opposed to infamous) engineers more or less susceptible to ethical failings than those who have not achieved notoriety outside their immediate employment and hence are more invisible to careful scrutiny? It is the contention of this paper that the famous and the not so famous, the self-employed and the gainfully, privately employed are equally likely to have an opportunity to be exposed to ethical dilemmas that can encroach the unsuspecting engineer at any time. It is also

"Proceedings of the 2001 American Society for Engineering Education Annual Conference \& Exposition Copyright $($ ) 2001, American Society of Engineering Education 
the author's contention however that there are several characteristics that help them become immune to the tendency to chose the "easy way out" of an ethical dilemma. The favorable characteristics for all such untouchables is a strong self worth as may be exhibited by confidence in his/her technical abilities but also in their moral judgments.

It is the focus of this paper to delve into what promotes an engineer's self worth and how to maintain this self worth and to thus avoid, what this author believes, is the primary cause of an ethical failing: fear. Fear of non-acceptance by an employer. Fear of loss of income. Fear of hurting or disabling, even if only temporarily, his/her family from the loss of income. Fear that no other employer will hire him/her.

\section{Self-employed or working for an employer: Does either ease the susceptibility to ethical dilemmas?}

Before discussing the avoidance of ethical dilemmas it is important to consider whether there is a simple solution to the problem. Can the avoidance of having a Boss (i.e. being self-employed, rather than employed by someone else) solve the problem of fearing the consequences of being the whistle blower? After all, if there is not a manager-in-charge who can pose the unethical challenge then will the engineer ever need to make a decision on an ethical dilemma? This is perhaps equivalent to the old philosophical question of whether a falling tree makes a noise in the forest if there's no one around to hear it?

That the absence of a manager-in-charge may eliminate the ethical dilemma has some basis in truth if one considers the results of the clinical test done by Mr. Stanley Milgram during the 60's. Mr. Milgram is famous for testing whether a human subject "lost' self control and/or independence of thought when surrounded by ranked-superiors or "people in charge". His testing revealed that the phrase "...I was only following orders..." is often used to dismiss personal responsibility for actions that have a clear moral and ethical consequence. Mr. Milgram's experiment was conducted with three individuals. Two of these individuals were actually part of the experiment and worked together to determine the responses of the third individual, the true "subject" of the experiment. The Subject of the experiment was asked by one of the participants who were put-in-charge of the experiment, to inflict punishment on the third participant if that participant gave an incorrect answer to a series of questions. The punishment (electric shocks of increasing voltage) was to get stronger upon every wrong answer. The third party was physically restrained in a chair but always visible to the principal Subject of the experiment. The Subject of the test would be asked/commanded to inflict the punishment by the person-in-charge. In repeated trials with different Subjects, over 50 $\%$ of the Subjects continued to administer the shocks even though the restrained participant could be seen by the Subject to be in obvious pain each time the punishment was inflicted. The Subject, who was "... only following orders", continued to administer the painful punishments to the third and completely defenseless participant in the experiment.

This example is often used to indicate how the majority of persons put entirely too much faith in the judgment of their "superiors" even in the face of obvious ethical and moral

"Proceedings of the 2001 American Society for Engineering Education Annual Conference \& Exposition Copyright $($ ) 2001, American Society of Engineering Education 
misjudgments. Based on these test results, it is fair to suggest that an engineer who has been asked (commanded?) to pick the wrong solution in an ethical dilemma would argue that it is their superior's who are ethically responsible for that wrong decision. It is therefore reasonable to assume that if an engineer did not have a superior or "managerin-charge" to answer to, then the engineer may be forced to at least grapple longer with the ethical dilemma and give it much more serious thought before deciding upon the ethical solution.

Then would being a self-employed engineer remedy the problem of susceptibility to ethical dilemmas? Or do they not also suffer from the temptation of and the need to decide between ethical dilemmas? Is self-employment a ready-made answer to avoiding the ethical problems that face the less strong-willed engineer?

This author would say that the answer to being impervious to ethical dilemmas lies beyond simply being self-employed. As an example, although fictional compared to the scientific lab tests of Mr. Mailgram, consider the psychological thriller offered in one episode of the famous anthology Twilight Zone, which appeared to audiences in 1960's. The story concerns a mysterious stranger who brings with him an even more mysterious, small cubic shaped box with only a thumb-size, push-button prominently exposed on one of its faces. The stranger picks a typical couple at random, ventures to their home and suggests to them that they can be the winners of a hefty amount of cash, no questions asked, if they only press the button! The catch? Pressing the button will most certainly kill an innocent, anonymous victim and stranger (to them) somewhere in the world. There will be no questions asked. There will be no ramifications to the button-pushing couple. No one will ever know if they press the button. Only they will know. The ethical dilemma: do they press the button to win the cash?

In the fictional story and, no doubt for dramatic effect, the answer is yes. The buttonpushers do indeed push the button and someone (not shown to the audience) is assumed to have silently been eliminated, without any outward signs that the rest of humanity is aware or even cares that an injustice and an immoral act has just been committed. The story ends but not before the ultimate consequences of their action is finally brought home to the perpetrators (and the viewing audience). When the unemotional stranger turns to leave, the now wealthier couple ask: "So what happens now?". The stranger responds, as he hands over the cash to the button-pushers: "You're in the clear, unless of course, at my next stop, the new button-pushers decide to act in a similarly manner and then, if Lady Luck spins the Wheel of Chance and it stops on either of your names, then and only then will you become the new "anonymous stranger" to the new button-pushers The scene then literally and figuratively, slowly fades to black.

To this author's knowledge there has not been a scientifically controlled experiment to demonstrate the preponderance of what people would actually do in this situation: Press or Not Press the button....with no Boss to assume responsibility, with no consequences for the ethical or unethical decision... no one will ever know. The parallelism with the current topic is clear. The button-pushers are not being compelled by an authority. They

"Proceedings of the 2001 American Society for Engineering Education Annual Conference \& Exposition Copyright $@ 2001$, American Society of Engineering Education 
cannot claim that they are “...only following orders". They can't claim that they were in fear of being punished via loss in pay or job. Do they push the button? Would you push the button? The self-employed engineer plays the role of the potential button-pushers in this example (or the non-button-pushers, as the case might be).

\section{What's the answer to avoiding an ethical dilemma?}

The answer to eliminating or significantly reducing the ethical dilemma faced by engineers does not lie in choosing a career path that provides self employment or employment in either a small or large company. As the experiments described above indicate either life style can provide an ethical temptation simply because the common denominator is still the fact that the engineer who is the subject to ethical quandaries is in fact a human with human failings and choices. What then is the common denominator for a sure bet, failure free action that will thwart ethical failings? The only correct answer to this quandary is that there is, in fact, no $100 \%$ remedy. Engineers can only hope (dare I say: expect) 100\% solutions when they can apply their education and experience and universal natural physical laws to tangible problems.

After all, the resolution to an ethical dilemma, with its sometimes philosophical twists and turns, is not what engineers are accustomed to handling. Or is it? Can it be made to be?

This author believes that there is within the typical engineer's training and life style attributes that can be mustered to maximize the chance that typical human weaknesses can be overcome with regards to engineering ethical dilemmas. The answer lies in the achieving of self-worth through supreme and unwavering confidence in you. This selfawareness and coincidence comes with a continual learning of the engineer's craft, a continuous gathering of state-of-the-art competence in the engineer's field of study and then the administration of this confidence and competence via a charismatic, positive attitude.

\section{Competence, Confidence and Charisma is the Answer}

It is the author's opinion that the proud and unflinching wearer of a defensive shield constructed of competence, confidence and charisma can thwart any attempt to violate the engineer's integrity. It is certainly not the most perfect defense but it is better than any other method for wearing down the opposition who would attempt to compromise an ethical code of moral behavior.

Competence is required in all professional fields. It is the benchmark of a professional. True competence in a chosen field of interest also serves however to embolden the individual with a real and unwavering presence and positive attitude. That attitude is confidently maintained and assured of its destination even if the winding path that is being taken does not always have the goal in sight. Competence eliminates the question in the engineer of whether there is in fact an alternative (less ethical solution) to the quandary. Competence knows that the $2+2=4$ and not possibly allowing an alternative answer, if only this once, of 2.01. It is confidence that enables the engineer to be

"Proceedings of the 2001 American Society for Engineering Education Annual Conference \& Exposition Copyright (0) 2001, American Society of Engineering Education 
convinced that the path that he/she has embarked upon is not a false one even when the road signs along the way have been intentionally removed or even just altered by the offending parties in an attempt to detour the engineer's judgement.

Confidence is that elusive property that can be sometimes true or false if it were not also powered forthrightly and definitively by competence. Once fortified by competence the individual is on surer, confident footing that the path undertaken will eventually lead to the desired, ethical objective. If the engineer has confidence built upon his/her unquestionable competence in formulating a decision based upon known facts, then the engineer is shielded against solicitors of unethical behavior who are either knowingly breaching the ethics of a situation or who have a lesser competence and thus are falsely promoting the untoward behavior not even suspecting the unethical realities.

Once confidence has been bolstered by competence it remains to be delivered, forcefully and professionally by the engineer to the offending source. It is only human nature that instruction of any sort is more receptive if the presentation of the counter-arguments is not itself threatening while also exuding an overwhelming air of knowledge (competence) and positive attitude (confidence). The overall objective is to deliver an ethical solution that is acceptable as an alternative to the originally proposed unethical proposition while seamlessly appearing to be a mutually arrived at solution.

\section{How Does the Shield Work?}

This force field of competence, confidence and charisma that protectively envelops the engineer works in several ways.

First and fore most, the mere outward and very visible appearance of the presence of the shield is itself an imposing barrier. A shield that can sometimes prevent the request for unethical behavior from being brought to the attention of the engineer. This author cites, as way of example, historical characters that were confident, competent and charismatic. Could Leonardo da Vinci, Albert Einstein or Richard Feynman be tempted toward unethical behavior if it involved physics or even the humanistic consequences of their engineering and physics? ${ }^{1}$

Could any philosophical/religious leader, whether it is Confucious, Moses, Buddha, Jesus or Mohammed be tempted away from an ethical question? And more to the point, who among their (chronological) contemporaries would have been bold enough to even suggest the unethical behavior. This is not to imply or infer that $21^{\text {st }}$ century engineers (or any professional) are as noteworthy in their chosen professions as these leaders (and the many more not cited here) were in theirs; although this goal would be admirable. The argument that is made is simply this: that a first defense against an ethical onslaught is an aura of impunity; of impenetrable shielding. This defense avoids the ethical dilemma by having it never brought to the engineer's attention in the first place by an administrator, a boss or client.

\footnotetext{
${ }^{1}$ It is well known that in a fit of creative development, da Vinci engineered the preliminary details of a viable submarine design but then abandoned the idea when he also envisioned the violent loss of life that would ensue in submarine warfare.

"Proceedings of the 2001 American Society for Engineering Education Annual Conference \& Exposition Copyright (C) 2001, American Society of Engineering Education
} 


\section{"Never Give Up...Never Give Up... Never Give Up"..."}

But what of the instances when the perpetrators of an unethical dilemma are embolden to pose the dilemma upon the engineer, regardless of how forthright and invulnerable that engineer might appear? After all, many of the historical figures mentioned above were tested at least once before their invulnerability was manifested and their shielding thus fortified from then onward. What can be the successful response to this first 'testing' onslaught?

The answer can only be the continuous administration of that personal competence and confidence that ultimately is the fabric of the shield that has yet to become visible to the onlookers. There's inevitably the first "test under fire" for any endeavor. The successful proof test becomes the unquestionable verification that the reinforcing structures upon which the shield is to be built have integrity. The successful test then becomes a tangible testimony to all those who care to witness the evidence that the ethical integrity cannot be compromised. In this manner, hopefully subsequent proof testing will not be necessary.

Successfully passing the proof test is indeed the ultimate objective of the engineer who is in a life long training for moral autonomy. The competence gained through education and experience can best be exhibited to the offending party ${ }^{3}$ through a steadfast application of a charismatic delivery. The presentation of the ethical engineer's point of view must be as deliberate and bold as it is accurate and precise but should not be mixed with animosity or demeaning for such an attitude only invites further contentiousness. The offending party must quickly recognize that the ethical engineer has an alternative point of view that is in fact justified and immovable. But then the offending party must be given an alternative and assessable path to escape from their previous arguments and strongholds.

In point of fact, the instruction that can be performed by the ethical engineer is usually welcomed by the offending party. The author recognizes that this last statement may be seen as naïve considering that the offending party is likely to be in a managerial (hence superior) position than the engineer who has just been asked to compromise his/her ethics by this very same manager. The criticism of naivete is acceptable to the author if there is at least some concurrence by the reader that most Managers, taken as an individual and separate from collective, i.e. Company, seek to administer solutions to problems in an ethical manner. It must be rare, the author contends, that the Supervisor purposely seeks the unethical solution when a positive, ethical solution is made apparent by the ethical engineer; a solution that is very likely even easier to attain. It is the author's opinion that the competent and confident engineer is exactly the party to administer an ethical and practical solution to a problem that at first appears to have no ethical resolution. The ethical engineer must approach the solution to an ethical dilemma

\footnotetext{
2 Winston Churchill's entire Commencement Address to Oxford University

${ }^{3}$ One may more politely call them the Test Engineers, if this author's habit in this paper of calling them 'perpetrators' or 'offending party' is offensive to some.

"Proceedings of the 2001 American Society for Engineering Education Annual Conference \& Exposition Copyright (0) 2001, American Society of Engineering Education
} 
in a manner that resembles the training and methods reserved for the more technical of engineering problems: by confidently and creatively applying his/her competence to the solution of the problem until the simplest most elegant solution has been achieved and with the acceptance or at least the acquiescence of all parties concerned.

\section{Dollars and Sense}

Eventually the bottom line answer to an ethical dilemma involves money. Either the cost of the engineer's proposed remedial actions is too expensive or equivalently, the cost of ignoring the ethical problem is less expensive, even when accounting for the loss of life. This is when the engineer's competence and the charisma can be most effectively put to work. If economics is given as the reason for the hesitancy from management in adopting the engineer's viable, ethical solutions then the engineer must strive to balance the equation by insisting upon using the true value of human life which must and can be rationalized by the engineer to be an enormous figure indeed; approaching infinite costs if necessary to balance the equation. The cost of the human life must be made to truly represent the value. The magnitude must be large enough to account for the ramifications caused to an industry (and not just the company) when human life is jeopardized and/or undervalued.

In terms of strictly dollars and cents, the engineer can quickly report the loss in future sales from bad publicity, the cost of law suits, the cost of future insurance coverage, the cost of law suits, the cost of low moral among the engineers who need to work for respected employers, the cost of law suits, the cost of investor's losing confidence in the publicly traded stock and above all: the cost of law suits! As you can see here, the cost of lawsuits cannot be mentioned enough as a means of making the Dollars make Sense when evaluating the economics of a solution to an ethical dilemma.

\section{Avoiding Self-Inflicted Wounds}

But how does one protect against the self-administered temptations to "push the button" on an unethical question particularly when there is no one present whose orders had to be followed. This is in fact a more difficult problem. The appearance of a possible unethical question is often missed by the very busy engineer whose defenses are literary "down"; not suspecting an ethical dilemma to intrude the normal business of the day. Can the use of the individual's competence, confidence and charisma thwart the ethical dilemmas that arise from within but are sometimes not recognized as dilemmas?

Here again all of the above applies. Assuming that some (most) ethical engineering problems only arise when an atypical incident of incompetence is quietly discovered by the ethical engineer, the ethical dilemma that is now presented is whether the engineer should voluntarily offer to rectify the problem which otherwise may go undiscovered. Certainly, the reader would argue: "If the ethical engineer has competence then this ethical dilemma doesn't occur because there would not ever be a significant engineering error caused to be discovered". But this is not a sufficient answer. Engineers, even ethical engineers, are human and mistakes are made in any profession.

"Proceedings of the 2001 American Society for Engineering Education Annual Conference \& Exposition Copyright () 2001, American Society of Engineering Education 
What of the instances when an error is discovered by the culpable engineer, what can then guarantee that he/she will administer his/her ethical oath properly and publicly acknowledge the initial failing? The only solution can be the engineer's inherent and perhaps continuously trained confidence and self-awareness (the goal of moral autonomy as cited by Messrs. Martin and Schinzinger, ref.1) to derive a solution to the problem even as the deficiency of the engineering solution is uncovered. The ethical engineer must be thus understanding of his/her potential for error but more strongly aware of his/her competence to resolve these errors either individually or with the qualified assistance of others.

The most striking example of this empowerment is the story of the structural engineer, Mr. William LeMessurier as told in The New Yorker article "The Fifty-Nine-Story Crisis" (May 29, 1995, pp45-53). Mr. LeMessurier discovers very late, after the construction of his most recent high rise building that a probable combination of wind forces, direction and duration could induce higher than expected forces on the structure of the building possibly causing it to fail within the normal life expectancy of the building. Does Mr. Le Messurier admit to his initial errors or does he ignore the problem. Does he push the button of accepting fame and fortune now at the expense of some (probabilistically: distant) future catastrophe caused by his non-action? In this instance, the engineer confidently, competently and with considerable charisma derives the solution to the problem, gathers the proper people to implement the solution (technicians, welders, iron workers as well as CEO's) as a team and rectifies the problem. The button is not pushed for the immediate fame but also the latent infamy that it can bring. In stead, the button-pressing is withheld to suffer the initial doubts of incompetence but then eventually the longer lasting approval of knowledgeable peers.

\section{How and When this manifest of Competence, Confidence and Charisma Achieved?}

It can only be achieved through a continuous dedicated effort at education and selfadvancement and it should begin as soon as possible in the education of the engineer. Dr. Abraham Maslow the noted humanistic psychologist offered his Maslow pyramid of the Hierarchy of Needs as a means of identifying how individuals can continue to grow as human beings and thus continue to contribute to a worthwhile life. Advancement via education is the means of achieving the truest reward: Self-Actualization or the fulfillment and realization of one's potential. Continuous education for the engineer is not a new phenomenon. However, it has been more closely associated with keeping current in order to maintain marketability than it has been to the contribution to the ethical fortification of the engineer. These two results are certainly not contrary. It is this author's contention that the need to stay current or competent in one's chosen field of study must be complimented by keeping informed in a variety of seemingly unrelated fields of study. The variety can only provide an additional self-assurance and confidence in making a final decision on any ethical matter. The level of diversity of information and experience that the engineer can bring to resolving a problem independent upon an outside source of information enables the decision that must be made regarding an ethical matter to be truly decisive if not immediate. Thus education has probably more

"Proceedings of the 2001 American Society for Engineering Education Annual Conference \& Exposition Copyright $($ ) 2001, American Society of Engineering Education 
of a contribution to the ethical development of the engineer and probably will be used more often by the engineer than its ability to help the engineer find a new job.

The exercise of continued and varied education should begin immediately. The sooner that the individual (soon to be an engineer) gains confidence through competence, then the sooner does the defensive shield become apparent to all who need to see it. And so also does the shield become stronger with time as additional layers of shielding is added through education and practical experience as the professional engineer's career matures.

Ultimately the true impunity to ethical dilemmas is strengthened by the engineer's supreme confidence in him/herself. A confidence that is enlivened by the acknowledgment of strong competences and which can be administered and defended, if necessary, by a charismatic delivery and posture.

\section{If All Else Fails...}

The actions suggested in this paper may not be enough to withstand the constant and demoralizing onslaught of an uncompromising ethical dilemma. The engineer's resolve to act only ethically may necessitate his/her voluntary departure. This should be the last and not the first act of the professional. The engineer who wears the "white hat" in any organization may be the only advocate for ethical performance by that organization. If that engineer decides to leave prematurely, before the ethical engineering point of view can be made, then it is possible that there will be no one left to intervene and offer the ethical argument(s). The end result is the public who will be the ultimate loser.

It would certainly be naive for this author to suggest that this action come easy, if at all. It is never the less important to indicate here that the characteristics of competence, confidence and charisma can be instrumental in guiding the professional engineer into a newer and hopefully cleaner environment where such characteristics are not only valued but fostered.

\section{CONCLUSION}

In the language of the 1980's, the mantra of “...just say No!” may be applicable but perhaps not always sufficient in those situations when the ethical engineer is requested to compromise his/her moral autonomy. The engineer must counter the expressions of the offending party with not only better arguments but with arguments that are completely defensible. This paper's objective has been to discern that the engineer's strength in delivering a convincing, charismatic argument in defense of the ethical resolution of a dilemma is well grounded in the engineer's competence and confidence, acquired through due diligence in his/her continuous education and professional experience.

It is the signature of the most professional and ethical engineer that the attempt at arriving at an amenable but ethical solution does not waver until that solution is attained. If the attempt to gain a solution to an ethical problem never ends then hopefully the offending party can and will choose the most complete solution available and literally

"Proceedings of the 2001 American Society for Engineering Education Annual Conference \& Exposition Copyright $($ ) 2001, American Society of Engineering Education 
resolve the engineer's ethical dilemma. If the engineer must ultimately terminate the relationship in order to uphold his/her ethics then the qualities of competence, confidence and charisma that have been espoused in this paper as the professional engineer's shield will assuredly continue to serve him/her well in all future endeavors.

\section{Biography:}

Francis A. Di Bella, PE is an Assistant Professor, Northeastern University, Boston, MA.; College of Engineering, School of Engineering Technology. Mr. Di Bella's professional engineering research interests involve the practical, engineering applications of Thermo-fluid and Machine Design sciences within the Mechanical Engineering discipline.

Specific areas of interest include all aspects of energy systems including generation, storage, conservation and a variety of innovative applications of wind, solar and hydropower. Such systems and their application include gas and steam engines (reciprocating, gas and steam turbines) with steam generation and steam turbine cogeneration of ancillary power. Engine power augmentation including turbo compounding, micro-turbine power generation using turbo-charger machinery for stationary electric power generation and use. Interest extends to the thermodynamic modeling of cogeneration systems and their size vs. cost optimization. This interest is exhibited in course instruction in heat transfer, thermodynamics, fluid dynamics.

Prof. Di Bella is also involved in all aspects of creative product concept genesis, design and product development. Product development extends the gamut from systems to prevent Road Rage to emergency repair of ruptured natural gas pipelines. University application of this interest includes instruction in the following courses: Machine Design, Statics and Dynamics, Intro. to Design and Intro. to Product Design as well as student Capstone Design Projects. He is also the Faculty Advisor for the Student's MiniBaja vehicle competition. 